\title{
Platelets and cancer angiogenesis nexus
}

\author{
Marek Z. Wojtukiewicz ${ }^{1,2}$ Ewa Sierko ${ }^{1,2,3}$ - Dominika Hempel ${ }^{1,2,3}$. \\ Stephanie C. Tucker ${ }^{4} \cdot$ Kenneth V. Honn ${ }^{4,5,6}$
}

Published online: 5 July 2017

(C) The Author(s) 2017. This article is an open access publication

\begin{abstract}
There has been remarkable insight into the importance of platelets in a wide range of pathophysiologic events, including inflammation and cancer progression. Thrombocytosis in cancer patients is a common finding. Tumor cells induce platelet activation and subsequent aggregation through direct and indirect mechanisms. Platelets are recognized to contribute to metastatic dissemination. There is plenty of evidence that components of the hemostatic system contribute to the process of angiogenesis. Furthermore, there are accumulated data on the substantial influence of blood platelets in the process of blood vessel formation during malignancy. Platelets appear to be the main physiologic transporters of proangiogenic and antiangiogenic factors. Moreover, they influence the process of angiogenesis through platelet-derived microparticles, microRNA, lipids, and variety of surface receptors. Platelets contribute to early and late stages of angiogenesis. Available data support the overall stimulatory effect of platelets on tumor angiogenesis. It raises
\end{abstract}

Marek Z. Wojtukiewicz

mzwojtukiewicz@gmail.com

1 Department of Oncology, Medical University, 12 Ogrodowa St., 15-027, Bialystok, Poland

2 Department of Clinical Oncology, Comprehensive Cancer Center, Bialystok, Poland

3 Department of Radiotherapy, Comprehensive Cancer Center, Bialystok, Poland

4 Bioactive Lipids Research Program, Department of Pathology-School of Medicine, Detroit, MI, USA

5 Department of Chemistry, Wayne State University, Detroit, MI, USA

6 Department of Oncology, Karmanos Cancer Institute, Detroit, MI, USA the possibility that interfering with platelet function may be an effective antineoplastic treatment strategy.

Keywords Platelets $\cdot$ Angiogenesis $\cdot$ Cancer .

Microparticles $\cdot$ Growth factors $\cdot$ MicroRNA $\cdot$ miRNAs

\section{Introduction}

Platelets, discovered by G. Bizzozero in 1882, were primarily recognized to play a role in hemostasis and thrombosis [1-3]. The presence of a thrombus accompanying cancer cells was observed over 130 years ago, and trombophilic state, both subclinical and clinically overt, is a frequent finding in cancer patients [3-7]. Thromboembolic complications may precede the diagnosis of cancer ("occult cancer"), occur during the natural course of neoplastic progression or be a complication of an oncologic treatment [8,9]. Thrombocytosis, a paraneoplastic syndrome, frequently accompanies cancer growth and metastatic dissemination. It is observed in as many as $10-57 \%$ of cancer patients [6-10]. High platelet count correlates with poor prognosis in patients with colon, lung, gastric, renal, prostatic, cervical, endometrial, and ovarian cancer and in malignant mesothelioma [11-19]. Pretreatment thrombocytosis is a poor prognostic factor as well and reflects aggressive tumor behavior in malignant mesothelioma, cervical, colon, and non-small cell lung cancer patients [20,21]. On the contrary, in pancreatic cancer patients, thrombocytopenia was associated with worse prognosis, thus indicating varied influence of platelets dependent on the type of cancer [22]. There is increased platelet turnover in cancer patients compared to healthy individuals, which corrects itself after anticancer treatment [23].

There has been remarkable insight into the importance of platelets in a wide range of pathophysiologic events, including 
inflammation and cancer progression. Platelets are recognized to contribute to metastatic dissemination [24, 25]. In experimental mouse models, inducing thrombocytopenia was associated with a diminished rate of metastases [26], whereas injection of human platelets to thrombocytopenic mice resulted in increased number of metastases in vivo [26, 27].

Formation of new blood vessels from pre-existing ones is a prerequisite of primary tumor growth, cancer cell intravasation, extravasation, and growth of cancer foci at distant sites [28-32]. It is widely known that angiogenesis is a rate-limiting process in cancer progression [29, 30]. There is plenty of evidence that components of the hemostatic system contribute to the process of angiogenesis [31-37]. Furthermore, there are accumulated data on the substantial influence of blood platelets in the process of blood vessel formation during malignancy [33]. Platelets appear to be the main physiologic transporters of the most important proangiogenic factor, vascular endothelial growth factor (VEGF), which implies their contribution to cancer angiogenesis as well [38]. The above hypothesis is supported by evidence that platelets are activated in tumor vasculature, which enables them to secrete their releasate directly within malignant tissue where they release VEGF upon activation [39-41]. Moreover, platelets stimulate capillary growth in vitro and angiogenesis in vivo [42, 43].

\section{Platelet structure and function}

Platelets are the smallest as well as the most numerous morphologic blood elements $\left(2 \times 10^{8} / \mathrm{mL}\right)$ and are characterized by a short turnover time ( 5 to 7 days). These anucleated blood constituents are surrounded by a phospholipid membrane. The outer platelet membrane is composed of glycoproteins and is enriched with integrins that contribute to the adhesive and aggregative processes. Among integrins, the most important are glycoproteins: Ib-IX-V (GP Ib-IX-V), VI (GP VI), and IlbIIIa (GP IIb-IIIa, also known as integrin $\alpha \mathrm{IIb} \beta 3$ ) [44-46]. Additional receptors in the platelet membrane include are protease-activated receptors (PAR-1 - responsible for majority of thrombin activity - and PAR-4) [47], adhesion molecules from immunoglobulin and selectin families [44], as well as purinergic P2 receptors for nucleotides (adenosine diphosphate (ADT) and adenosine triphosphate (ATP)) [48]. Endothelial cell damage or alteration leads to exposure of the subendothelial extracellular matrix (ECM) components that are ligands for platelet adhesion and include various types of collagen, von Willebrand factor (vWF), laminin, vitronectin, proteoglycans, thrombosposndin, and fibronectin [49]. At high shear stress, collagen and collagen-bound vWF are important for platelet adhesion and activation [50]. The latter reversibly interacts with platelet GP Ib-IX-V resulting in reduced platelet velocity and platelet rolling over the collagen surface. This glycoprotein also facilitates plateletendothelial cell (EC) adhesion (through P-selectin) and platelet-leukocyte adhesion (through Mac-1) [44]. In addition, vWF binds to platelet GPIIb-IIIa producing a bridge between platelets and collagen [51]. Firm adhesion of platelets to collagen is directly mediated by GPVI and GPIa-IIb [49], which, in turn, induces their activation and increases cytosolic calcium concentration. At low shear stress, GPVI binding to collagen sufficiently mediates adhesion and activation of platelets [44, 45]. During platelet activation, phosphatidylserine (PS) is exposed on the outer side of the membrane and microvesicles enriched with PS facilitate procoagulant activity [52]. Furthermore, upon activation, platelet membranes form many invaginations that extend their active surface. The cytoskeleton of the platelet is composed of numerous cross-linked elements, mainly actin, that connects with the cytoplasmic domain of GPIb-IX complexes as well as GPIa-IIa complexes [53]. Under physiologic conditions, the shape of platelets is discoid. However, upon activation, actin polymerizes and its subunits are rapidly reassembled into a variety of new structures such as filopodia and lamellipodia to dramatically generate new platelet shapes (balloon-like) depending on the external forces, extracellular signals, and physiologic requirements [54, 55]. Once activated, platelets form plateletderived microparticles (PMPs) and exosomes and provide a source of nucleic acids as well.

Platelets are enriched in three types of specific granules ( $\alpha$ granules, dense granules, and lysosomes) that store a diverse array of products, as well as mitochondria and a dense tubular system that facilitates delivery of energy and biochemical messengers that contribute to platelet reactivity [56]. Alpha granules (50-80 per human platelet) are most numerous and store large proteins that play a role in adhesion and aggregation. Dense granules (three to eight per human platelet) are enriched with small non-protein molecules and have far fewer factors that upon secretion facilitate recruitment of other platelets $[56,57]$. Lysosome function is not well characterized, but they are loaded with hydrolases that participate in the elimination of platelet aggregates [56, 57] (Table 1).

\section{Thrombocytosis in malignancy}

Thrombocytosis in cancer patients is a common finding. However, mechanisms underlying this phenomenon are not fully understood. A variety of tumor-related humoral factors and cytokines influences thrombopoiesis in cancer. Among them are granulocyte colony-stimulating factor (G-CSF), granulocyte macrophage colony-stimulating factor (GMCSF), interleukin-6 (IL-6), interleukin-1 (IL-1), and thrombopoietin (TPO) [58-63]. Elevated serum levels of TPO were observed in cancer patients with reactive thrombocytosis [64]. It was documented that several tumor 
Table 1 Platelet releasate from three major forms of storage granule products: $\alpha$-granules, dense granules, and lysosomes $[33,57]$

\author{
Platelet Constituents \\ granule \\ $\alpha$-Granules $\quad$ Adhesion molecules (e.g., vWF, $\alpha \operatorname{IIb} \beta 3, \alpha \mathrm{v} \beta 3$, P-selectin, thrombospondin, fibrinogen, \\ fibronectin) \\ Coagulation factors (prothrombin, fibrinogen, factor $\mathrm{V}$, factor VIII) \\ Fibrinolytic factors ( $\alpha 2$-macroglobulin, plasminogen, PAI-1, SERPINE1, uPA) \\ Growth factors (VEGF-A, VEGF-C, PDGF, bFGF, EGF, HGF, IGF1, TGF $\beta$ ) \\ Proagiogenic and antiagiogenic factors (angiopoietin-1, angiostatin, S1P) \\ Tissue remodeling matrix metalloproteinases (MMP-1, MMP-2, MMP-3, MMP-9, \\ MT1-MMP) \\ Tissue inhibitor of metalloproteinases (TIMPs: TIMP-1, TIMP-2, TIMP-4) \\ Disintegrin \\ Metalloproteinases (ADAMs: ADAM-10, ADAM-17, ADAMTS-13) \\ Proinflammatory mediators (CXCL1 (GRO- $\alpha$ ), CXCL4 (PF4), CXCL5 (ENA-78), CXCL7 \\ (PBP, $\beta$-TG, CTAP-III, NAP-2), CXCL8 (IL-8), CXCL12 (SDF-1 $\alpha$ ), CCL2 (MCP-1), \\ CCL3 (MIP-1 $\alpha$ ), CCL5 (RANTES), CCL7 (MCP-3), CCL17 (TARC), PAF, \\ acetylhydrolase, LPA) \\ Immunologic molecules ( $\mathrm{C} 1$ inhibitor, $\mathrm{IgG})$ \\ Other proteins (albumin, $\alpha 1$-antitrypsin, Gas6, HMWK \\ Dense Ions (calcium, magnesium, phosphate, and pyrophosphate) \\ granules Nucleotides (ATP, GTP, ADP, GDP) \\ Membrane proteins (tetraspanins, LAMP2) \\ Transmiters (5-HT, epinephrine, histamine) \\ Protease inhibitors (TFPI) \\ Lysosome Phospholipase A protease glycohydrolase enzymes
}

$\nu W F$ von Willabrand factor, $\alpha I I b \beta 3$ glycoprotein IIb-IIa, $P A I-1$ plasminogen activator inhibitor-1, $u P A$ urokinase plasminogen activator, $V E G F-A$ and $V E G F-C$ vascular endothelial growth factor A and C, $P D G F$ platelet-derived growth factor, $b F G F$ basic fibroblast growth factor, $E G F$ epidermal growth factor, $H G F$ hepatocyte growth factor, $I G F 1$ insulin-like growth factor $1, T G F \beta$ transforming growth factor $\beta, S 1 P$ sphingosine-1-phosphate, $M M P-1$, $M M P-2, M M P-3, M M P-9, M T 1-M M P(M M P-14)$ tissue remodeling matrix metalloproteinases), TIMPs: TIMP-1, $T I M P-2, T I M P-4$ tissue inhibitor of metalloproteinases, $I L 1-\beta$ interleukin-1 $\beta, P A F$ platelet-activating factor, $L P A$ lysophosphatidic acid, $\operatorname{Ig} G$ immunoglobulin G, Gas6 growth arrest-specific 6, HMWK high-molecular-weight kininogen, ATP adenosine triphosphate, GTP guanosine-5'-triphosphate, ADP adenosine diphosphate, GDP guanosine diphosphate, 5-HT serotonin, TFPI tissue factor pathway inhibitor

cell types can produce and regulate TPO, a key cytokine that stimulates megakaryocyte formation and platelet production, e.g., in ovarian cancer $[65,66]$. Recently, experiments performed with orthotopic mouse models of ovarian cancer demonstrated that tumor cell-derived IL-6 stimulates hepatic production of TPO [65]. Activated platelets are a rich source of microparticles (PMPs) that stimulate proliferation, survival, adhesion, and chemotaxis of hematopoietic cells [67]. There exists reciprocal interaction among megakaryocytes and ECs in the bone marrow $[62,68,69]$. Furthermore, it is now known that bone marrow endothelial cells (BMECs) support megakaryocytopoiesis [62]. Various cytokines, such as kit ligand, IL- 6 , and TPO are constitutively released by BMECs [62]. It was documented that BMECs support proliferation and differentiation of megakaryocytic progenitor cells in vitro as well as facilitate the growth and maturation of megakaryocytes in vivo [62]. Megakaryocytes release not only cytokines, including IL-1, IL-3, IL-6, and GM-CSF, but also factors essential for the stimulation of angiogenesis, such as VEGF and basic fibroblast growth factor (bFGF) [41, 69, 70]. Hypercoagulability and excessive thrombin generation, commonly observed in the course of malignancy, may contribute to thrombocytosis in cancer patients. In this context, it is of interest that bFGF induces megakaryocyte differentiation through modulation of megakaryocyte-stromal interactions and augmentation of cytokine secretion from megakaryocytes [71]. Moreover, bFGF increases megakaryocyte colony formation in vitro [72]. In turn, VEGF contributes to megakaryocyte maturation through an autocrine loop via the VEGF receptor-VEGFR-1. Permeability induced by VEGF may be of particular importance since it facilitates megakaryocyte transendothelial migration to the circulation [73]. Platelet infusion promotes bone marrow-derived cell mobilization into the circulation in an ischemic limb model, whereas platelet depletion inhibits the effects [74]. It should be emphasized that tumor-derived proangiogenic factors may facilitate the 
formation of megakaryocytes that is followed by increased platelet count. Reportedly, platelet count correlates with serum level of VEGF, but not with bFGF in patients with advanced cancer [75]. In turn, angiogenesis inhibitors, such as thrombospondin-1 (TSP-1) and platelet factor 4 (PF-4), inhibit megakaryocytopoiesis in experimental models [76, 77].

\section{Cancer-associated platelet activation}

Increased circulating levels of a platelet-specific $\alpha$-granule protein, $\beta$-thromboglobulin, as well as elevated expression of platelet adhesion molecules (e.g., CD62, CD63, P-selectin) reflect platelet activation. In many cancers (e.g., prostate, breast, lung, gastric, and colon cancer), particularly at an advanced stage of the disease, the $\beta$-thromboglobulin levels were significantly elevated [33, 78, 79]. Moreover, increased expression of platelet adhesion receptors was repeatedly reported in blood of cancer patients [80-82].

Adherence of platelets to ECs or ECM components is a prerequisite of local platelet activation and secretion. Of interest then is the mechanism of increased platelet tethering and adhesion in tumor vessels or in tumor-like environments [41]. Platelet adhesion to ECs is increased 2.5-fold after stimulation with VEGF [41]. Tumor-derived ECs are phenotypically and functionally distinct from ECs in normal tissues [83]. Tumor cells induce platelet activation and subsequent aggregation through direct and indirect mechanisms [24, 25]. Both tumors - released soluble stimulators and tumor cell surface molecules - contribute to cancer-related platelet activation $[24,25]$. Platelet aggregation in response to tumor cell stimulation is known as tumor cell-induced platelet aggregation (TCIPA) [25]. Indirect platelet activation by cancer cells is through activation of coagulation, which is mainly triggered in malignant disease by tissue factor (TF) present on cancer cells, tumor-infiltrating macrophages, and tumor ECs [33, 34, 84]. Thrombin generated in the process plays a main role among soluble stimulators of TCIPA. Cancer cells also have the ability to release procoagulant microparticles that also initiate thrombin generation [84]. Tumor-derived ADP, cathepsin $\mathrm{B}$, and matrix metalloproteinases also play an important role in TCIPA $[85,86]$. Tumor cells produce platelet agonists that mediate tumor cell-platelet interactions and influence the adhesion potential of both types of cells. Increased expression of adhesion molecules on platelet surfaces further intensifies the release of second mediators, which recruit more platelets to the site of interaction [25]. Adhesive properties of tumor cells themselves are responsible for direct interactions between platelets and tumor cells [78]. Likewise, integrins GPIIb-IIIa and GPIb present on platelet membranes play an important role in adhesion reactions with tumor cells in the process of platelet aggregation [79]. Sialoglycoprotein Aggrus/ podoplanin present in various tumor cell lines (e.g., glioblastoma, mesothelioma, lung, esophageal squamous cell carcinoma, and colon carcinoma) may also be involved in TCIPA [87, 88]. Namely, the C-type lectin-like receptor (CLEC2) expressed on platelets is a counter receptor of podoplanin. Binding of podoplanin to CLEC-2 transmits platelet activation signals via Src family kinases, Syk, and phospholipase $\mathrm{C} \gamma 2$ in platelets [89, 90]. Furthermore, physical binding of tumor cells and tumor cell-derived plasma membrane vesicles with platelets induces platelet aggregation. Platelets can be activated via cancer-induced formation of neutrophil extracellular DNA traps (NETs), that consequently leads to platelet aggregation and thrombus formation [91]. It should be emphasized that tumor cell-induced blood coagulation reinforces aggregation and platelet-mediated tumor cell adhesion to the ECs [92].

\section{Multidirectional role of platelets in angiogenesis in malignancy}

Active proliferation of tumor cells necessitates neovascularization to support optimal blood supply for growing tumor tissue in order to deliver necessary nutrients and oxygen, as well as remove waste products from the tumor microenvironment [28-30]. Through numerous studies, it is now apparent that angiogenesis is not only driven by tumor-derived proangiogenic factors but also by tumor microenvironment, stromal cells, and tumor-associated macrophages. Furthermore, reciprocal interplay between tumor cells and ECs contributes to the formation of new blood vessels. The hypothesis that platelets are involved in the process of angiogenesis was raised almost 20 years ago by Pinedo et al. [93]. The presence of activated platelets was observed in the tumor vasculature in sarcoma patients [94]. Platelets were implicated in early and advanced stages of angiogenesis, e.g., in the stabilization of newly formed vessels $[39,42,43]$. Platelets stimulate EC proliferation and tube formation in vitro and induce angiogenesis in vivo [40, 42, 94], which is dependent on platelet adherence to the differentiating ECs through their surface adhesion molecules [40, 42, 94]. Activated platelets induce TF expression on ECs by interaction between platelet CD154 and CD40 present on ECs to induce coagulation [95]. Ligation of CD40 stimulates expression of adhesion molecules, e.g., Eselectin, vascular cell adhesion molecule-1 (VCAM-1), and intercellular adhesion molecule-1 (ICAM-1) that enhances adhesion of inflammatory cells to the ECs [96]. As platelets adhere almost immediately to exposed or activated endothelium, and they are major storage and delivery vehicles for proangiogenic and antiangiogenic growth factors, bioactive lipids, cytokines, and chemokines, such as stromal-derived factor 1 (SDF-1), platelets orchestrate the local angiogenic stimulus within a tissue and direct the recruitment and differentiation of circulating bone marrow-derived cells (BMDCs) 
(Fig. 1) [97]. It was documented that platelets are required for BMDC recruitment into ischemia-induced vasculature [74]. Secretion of platelet $\alpha$-granules, but neither dense granules nor platelet aggregation, is crucial for BMDC homing and subsequent angiogenesis [74, 98]. Furthermore, platelets absorb and sequester tumor-derived proangiogenic factors and induce BMDC mobilization, which is counterbalanced by the antiangiogenic factor TSP-1. A lack of TSP-1 in platelets leads to an imbalance in proangiogenic and antiangiogenic factors and accelerates tumor growth and vascularization [74]. Platelets were demonstrated to stimulate BMDC homing in a VAMP-8-dependent manner [74]. Interestingly, it was revealed that human platelets take up cytokines released by luminal breast cancer cells and thereafter deliver them to indolent metastatic tumor foci, contributing to tumor growth via stimulation of vessel formation [99]. Recently, platelets have served as a form of surrogate biosensor as tumor-educated platelets have been used to screen for the presence or absence of cancer (96\% accuracy), as well as the type of malignancy (71\% accuracy) based on RNA content [100].

\section{Platelet releasate, receptors, and membrane constituents}

Platelet $\alpha$-granules contain, as mentioned above, proangiogenic and antiangiogenic factors [33]. What particularly links platelets with the process of angiogenesis is that platelet progenitor cells synthesize and release VEGF, while platelets transport and, upon activation, secrete VEGF, which is the most important proangiogenic molecule [38, 39, 41, 75]. The addition of thrombin into platelet-rich plasma from healthy subjects results in much higher VEGF levels than if thrombin is added into platelet-free plasma [101]. Inflammation, a process known to facilitate cancer

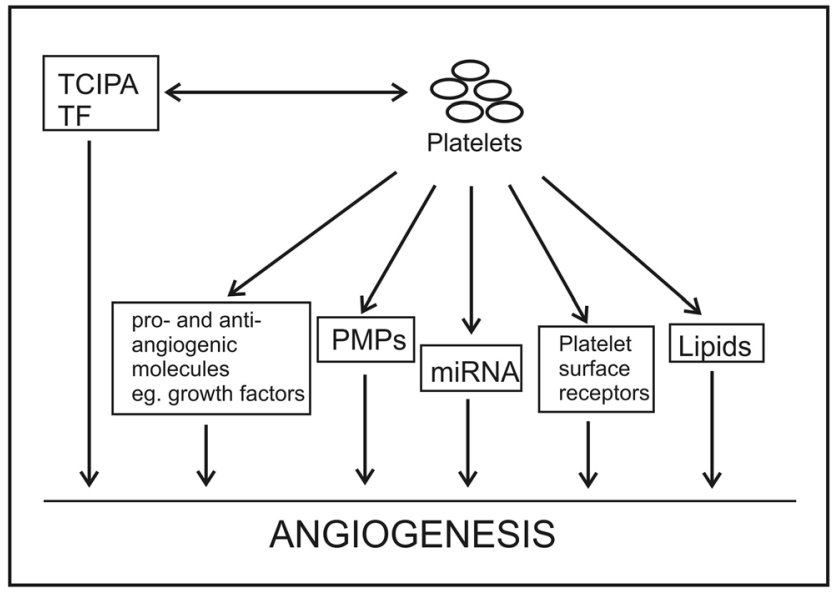

Fig. 1 Multidirectional influence of platelets on angiogenesis in malignancy. TCIPA tumor cell-induced platelet aggregation, $T F$ tissue factor, $P M P s$ platelet microparticles, $m i R N A$ microRNA progression, induces VEGF release from platelets in breast cancer patients [102]. Moreover, the platelet function is altered in cancer patients, as platelets from women with early breast cancer released significantly more VEGF upon thrombin or TF stimulation than platelets derived from healthy controls [103]. In breast, colorectal, renal, and ovarian cancer patients, the platelet count correlated significantly with serum VEGF content [75, 104]. Furthermore, the concentration of platelet-derived VEGF is a better predictor of tumor progression than serum VEGF levels [105]. High serum VEGF concentration per platelet count was associated with shorter overall survival [106]. Of interest is the observation that the ratio between serum VEGF and plasma VEGF tended to be smaller in metastatic breast cancer patients as compared to patients with locoregional disease, suggesting more intense intravascular platelet degranulation in the former group [24]. Cancer cells themselves synthesize VEGF as well as IL-6, that may be released into the bloodstream $[107,108]$. Tumor cells via IL-6 may exert an indirect effect on thrombocytosis and platelet uptake of free VEGF [108] that may facilitate the transport of VEGF to the site of tumor cell-EC interaction. Tumor cells circulate in the bloodstream in complexes with platelets [25]. Thus, at the sites of tumor cell adherence to ECs, platelets may release their VEGF content to induce permeability, facilitate extravasation of cancer cells, and facilitate angiogenesis at sites of distant metastases.

Tumor cell-derived VEGF may additionally induce the formation of fenestration in the endothelium, a process that leads to the exposure of subendothelial matrix to the circulating blood and consequently induces blood coagulation. Furthermore, VEGF stimulates ECs to secrete vWF, an adhesion molecule for platelets [109]. Irregularity, immaturity of tumor vasculature that is associated with numerous sites of blood flow stasis, and increased interstitial pressure greatly facilitate platelet adhesion to the vessel walls within the tumor. Platelet adhesion and subsequent activation, aggregation, and release promote rolling and adhesion of inflammatory cells on platelet and EC surfaces in the tumor vasculature [110]. All of the abovementioned steps proceed in a self-perpetuating manner to facilitate activation of blood coagulation and subsequent thrombin and fibrin formation.

Serum and platelet VEGF, through induction of vessel permeability, facilitate escape of hemostatic proteins and other macromolecules. It is widely recognized that proteins from the coagulation and fibrinolytic cascades contribute various functions in the process of new vessel formation [111, 112]. Fibrinogen deposited in the extravascular space both at the primary tumor and at metastatic foci forms an ideal surface for platelet binding. It also serves as a basis for EC migration and influences EC motility [32]. Fibrinogen per se also activates platelets. VEGF induces TF expression in ECs and tumor-associated monocytes/macrophages [113]. Tissue factor exerts its proangiogenic activity through its signaling 
function as well as the initiation of TF-dependent blood coagulation, subsequent thrombin generation, and fibrin formation $[31,34]$. Interestingly, VEGF induction of platelet adhesion to ECs and platelet activation is dependent on TF activity [94]. Thrombin generated by the TF-dependent pathway of blood coagulation exerts its activity via platelet PAR-1 and PAR-4 receptors $[111,112]$. Activation of PAR-1 leads to VEGF release from platelets, while activation of PAR-4 leads to the secretion of an inhibitor of angiogenesis, endostatin [114]. Thrombin stimulation results in VEGF/fibronectin complex release from platelets [115]. Binding of VEGF to fibronectin increases VEGF proangiogenic activity (e.g., promoting EC migration) [116].

VEGF supports transendothelial migration of monocytes and serves as a chemotactic factor for monocytes and mast cells [113]. Both tumor-associated monocytes/macrophages and mast cells contribute to angiogenesis in cancer patients $[116,117]$. These cells are an additional source of VEGF and other cytokines that indirectly stimulate angiogenesis [113].

Additional proangiogenic factors that are stored in platelet $\alpha$-granules and released upon platelet activation include VEGF-C (stimulates lymphangiogenesis), bFGF (facilitates migration, proliferation, and differentiation of ECs as well as regulation of the expression of other proangiogenic factors), epidermal growth factor (EGF; upregulates VEGF messenger RNA (mRNA) expression in vitro and induces the expression of FGF-binding protein that binds and activates both basic and acidic FGF), platelet-derived endothelial cell growth factor (PD-ECGF; a chemotactic factor for ECs in vitro and proangiogenic factor in in vivo studies), platelet-derived growth factor (PDGF; mediates angiogenesis via stimulation of VEGF expression in ECs localized at the tumor burden and through recruitment of pericytes to newly forming vessels), hepatocyte growth factor (HGF; stimulates the expression of VEGF and HGF itself in ECs as well as the synthesis of platelet activating factor (PAF) by macrophages that, in turn, promotes further platelet activation and increases EC migration), insulin-like growth factor 1 and 2 (IGF-1, IGF-2; mediates proteolytic events necessary in angiogenesis), transforming growth factor-beta 1 (TGF- $\beta 1$; increases EC survival and stabilizes capillary structures in the in vitro models of angiogenesis), angiopoietin-1 (Ang-1), and plasminogen activator inhibitor-1 (PAI-1) [33]. Alpha granules also contain PAI-1. Although it may be considered an angiogenesis inhibitor (diminishing the dynamic of proteolytic events), PAI-1 promotes angiogenesis [118]. In the experimental studies, new vessel formation was abolished in the absence of PAI-1 [119]. Interestingly, VEGF, platelet factor 4 (PF4), and PDGF are elevated in platelets of colorectal cancer patients [120].

Platelet $\alpha$-granules are a source of antiangiogenic factors as well. PF-4 bound to the surface of heparin-like glycosaminoglycans on ECs, blocks binding sites for heparin-binding endothelial growth factors, directly neutralizes the heparinbinding region of bFGF, and inhibits the EC stimulatory activity exerted by EGF and VEGF [33]. Thrombospondin-1 stimulates EC adhesion and spreading but inhibits the chemotactic response of ECs to bFGF. It may facilitate growth factor and integrin signaling pathways between ECs and block fibrin-induced EC motility [33, 121]. Smaller fragments of HGF (NK1-first HGF kringle domain, NK2-first two kringle domains) endowed with antiangiogenic activity are also stored in platelet $\alpha$-granules. They inhibit angiogenesis induced by HGF in experimental models [33]. Angiopoietin1 , considered an angiogenesis stimulator, in some circumstances may exert an antiangiogenic function as it inhibits endothelial permeability and IL-8 synthesis [33]. Angiogenesis inhibitor, angiostatin, was also identified in human platelets [122]. Platelet membranes constitutively generate angiostatin, the mechanism of which is dependent on uPA but not MMPs [123]. Endostatin is also in $\alpha$-granules [124]. Activation of PAR-4 contributes to the secretion of this angiogenesis inhibitor, while activation of PAR-1 leads to the suppression of endostatin release from platelets [124]. Furthermore, platelet membranes have receptors for growth factors [121, 125]. PDGF receptors are present on platelets as well as on their progenitor cells, megakaryocytes, where they function to enhance their proliferation rate [126]. Platelet PDGF- $\alpha$ receptors mediate negative feedback regulation [125].

Platelet membranes also have receptors for VEGF (both VEGFR-1 and VEGFR-2) [126, ]. While VEGF does not induce aggregation itself, it facilitates SFRLLN-stimulated or thrombin-stimulated platelet aggregation [127]. It may be suggested that platelets transport the receptors and transfer them to the site of neoangiogenesis through PMP formation.

The other type of platelet granules, dense granules, releases ADP, which was demonstrated to exert chemotactic activity toward ECs, thus facilitating migratory events [128]. However, recently, it was noted that neither dense granule content nor lysosomal secretion is critical for new blood vessel formation [43].

Platelets are surrounded by phospholipid membrane. Three constituents of the membrane possess proangiogenic activity, namely phosphatidic acid, lysophosphatidate, and S1P. S1P, a bioactive lipid released by activated platelets during blood clotting, is a potent EC chemoattractant [129]. It exerts its effect in a receptor-dependent process [129].

\section{Platelet-derived microparticles}

Activated platelets form microvesicles that are released into the blood [130]. Platelet remnants and microvesicles were found at sites of angiogenic sprouting [131]. 
Platelet-derived microparticles, known also as microvesicles, are the most abundant microparticle constituents in the peripheral blood, accounting for around $70-90 \%$ of all extracellular vesicles [132]. They are formed by cell membrane budding, and their size varies between 0.1 and $1 \mu \mathrm{m}$ [133]. Platelet-derived microparticles are constantly shed into the circulation at certain levels even in healthy people [134]. Some fraction of circulating PMPs originates from megakaryocytes [132]. An increased number of PMPs was observed in thrombotic disorders as well as in solid tumors and hematologic malignancies [132, 135]. Platelet activation, oxidative stress, tissue hypoxia, and activation of the coagulation cascade stimulate production of PMPs [136]. In addition to actively promoting tumor growth and metastatic dissemination, PMPs also promote angiogenesis [132, 134-140]. Platelet-derived microparticle function is multifactorial. They induce sprouting of new blood vessels both in vitro and in vivo to a degree comparable with that of whole platelets, and they enhance vascular permeability [139, 141]. They induce the procoagulant phenotype through PS-induced activation of blood-born TF or by triggering $\mathrm{TF}$ expression in monocytes that contributes to proangiogenic thrombin and fibrin formation [34, 130]. PMP membranes are also enriched with TF and display negatively charged surfaces where clotting factor complexes can assemble. This substantially induces blood coagulation and consequently tumor angiogenesis [31, 33, 34, 142]. They were documented to stimulate the expression of adhesion molecules on a variety of cells, promote the release of cytokines, influence vascular reactivity, and induce inflammation $[67,138]$. Platelet-derived microparticles can express and transfer functional receptors from platelet membranes, such as glycoprotein IIb-IIIa (GPIIbIIIa) and P-selectin, to different cell types [143], and as a consequence facilitate engraftment of hematopoietic stem/ progenitor cells [140]. They can transfer angiogenic factors intracellularly and can induce proangiogenic genes through direct cellular contact, e.g., with ECs or fusion with target cells, such as tumor cells or ECs [133]. Interestingly, the presence of PMPs in endothelial progenitor cell cultures was also observed [142, ]. PMPs chemoattract hematopoietic cells and induce their adhesion, survival, and proliferation [67]. Moreover, in vitro and in vivo studies demonstrated that PMPs promote proliferation and survival of ECs [138]. Furthermore, ex vivo studies demonstrated that PMPs stimulate progenitor cells to form a capillary network $[139,142]$. The platelet origin of PMPs results in the presence of proangiogenic growth factors (e.g., VEGF, PDGF, FGF) as well as metalloproteases in their $\alpha$-granules [133]. Moreover, PMPs stimulate secretion of proangiogenic factors by tumor cells [144]. PMPs have the ability to induce the expression of MMP-9, VEGF, and IL-8, all of which are known to be involved in angiogenesis [67]. Furthermore, in vitro PMPs stimulate prostate cancer cells to secrete MMP-2, which, in turn, facilitates their passage through collagen, a major component of ECM [145]. Interestingly, this secretion is not mediated by major intraplatelet proangiogenic factors, such as VEGF, bFGF, or platelet factor 4 [145]. PMPs are able to stimulate kinasedependent protein phoshorylation (MAPK p42/44 and AKT) and increase the expression of membrane metalloproteinase type 1 (MT1-MMP) that degrades components of the extracellular matrix to facilitate angiogenesis [140, 146]. Increased activity of MMPs was documented in many tumor types (e.g., MT1-MMP is overexpressed in lung cancer) [146]. Recently, it was reported that PMPs transfer proteins as well as DNA and RNA (including mRNA and miRNA) to recipient vascular cells and other cell types [147-149].

\section{MicroRNA}

MicroRNA (miRNA/miRs) are small non-coding RNAs, approximately $18-25$ nucleotides in length that are able to modulate post-transcriptional regulation of gene expression and function of protein-coding mRNAs in almost all key cellular processes, including, among others, angiogenesis, cell proliferation, migration, and apoptosis [150]. miRNA is transcribed in the nucleus by RNA polymerase II as a primary transcript called pri-miRNA [151]. It is recognized further by Drosha ribonuclease and its partner, the double-stranded RNA binding protein DGCR8 [152] that go on to generate precursor miRNA (pre-miRNA) of approximately 70 nucleotides [151]. The latter is then exported from the nucleus to the cytoplasm by exportin 5 (XPO5) [153] and cleaved by RNase III enzyme Dicer, RNA-binding protein 2 (TARBP2), and AGO2 (DICER complex). The processing produces a double-stranded miRNA-miRNA duplex* [154]. After separation of the two strands, the mature miRNA (the guide strand) is incorporated into the RNA-induced silencing complex (RISC), while the passenger miRNA strand denoted as * is incorporated into the RISC complex or degraded [155]. The mature miRNA guides the AGO protein of the RISC to the complementary mRNA sequence on the target to repress its expression [151]. The six to eight nucleotide sequence at the $5^{\prime}$ end of the loaded miRNA binds to the complementary sequence on the mRNA inducing their translational repression or degradation. Each miRNA is capable of regulating the expression of many genes; thus, each miRNA can simultaneously regulate a variety of cellular signaling pathways. Human platelets contain an abundant and diverse repertoire of miRNAs [156, 157] 
that may regulate platelet mRNAs, protein synthesis, and reactivity [157-159]. Platelets can release miRNAs directly into circulation as vesicle-free ribonucleoprotein complexes in association with Ago2 or high-density lipoproteins (HDL), or in exosomes, shedding vesicles, apoptotic bodies, and PMPs [160-163]. Since platelets release PMPs upon activation, and PMPs are the most abundant microvesicles in the circulation, they carry a substantial amount of miRNAs that potentially control angiogenesis [148, 157]. miRNA, e.g., miR-19, miR-21, miR-126, miR-133, miR-146, miR-223, has been detected in PMPs [149]. Delivery of functional platelet miRNAs into ECs via PMPs has also been demonstrated $[165,166]$, where activated platelets released functional miRNAs that entered into ECs to regulate endothelial ICAM-1 expression [165]. Furthermore, Laffont et al. [166], in an elegant study, documented that platelets activated with thrombin release miR-223 preferentially through PMPs that can be internalized by ECs (human umbilical endothelial cells (HUVECs)), leading to the accumulation of plateletderived miR-223. They also demonstrated that PMPs contain functional Ago $2 \times$ miR-223 complexes that are able to regulate (downregulate) expression of endogenous genes in recipient HUVECs, both at the mRNA (mRNA destabilization) and protein (inhibition of mRNA translation initiation) levels [166]. Platelet-released miR-223 promotes advanced glycation end product-induced vascular EC apoptosis by targeting insulin-like growth factor 1 receptor [167]. Platelet-derived miR-223 regulates $\mathrm{P}_{2} \mathrm{Y}_{12}$ receptor expression in platelets, suggesting accelerated platelet activation and aggregation that may contribute to further stimulation of angiogenesis [168]. Vascular endothelium damage increases the level of apoptotic bodies that induce the expression of SDH-1 in recipient ECs through importing miR-126 [163]. Additionally, miR126 targets the protein regulator of G-protein signaling 16 (RGS16) that is known to inhibit CXCR4 [163]. Consequently, this enables CXCR4 to stimulate an autoregulatory feedback loop that increases the phosphorylation of ERK1/2 and enhances the production of SDF-1 [163]. Furthermore, introduction of apoptotic bodies into an animal model by injection into the blood stream results in elevated levels of miR-126, and subsequent dysfunction of endothelium [168]. It was demonstrated that miR126 enhances vascular hemostasis by protecting endothelial integrity as it targets SPRED1 and PIK2R2 (inhibitors of EC growth signaling) [169]. Platelet-derived miR-140 directly targets SDF-1 in fibroblasts, which may also contribute to angiogenesis [170]. Furthermore, miR-221 and miR-222 target c-kit (tyrosine-protein kinase kit), endothelial nitric oxide synthase (eNOS), and p27/lip1 subsequently promote angiogenesis in vivo in response to stem cell factor [171, 172]. Given the immense diversity of platelet miRNA sequences [157] and the number of cell types capable of exchanging information by intercellular transfer [164], one quickly appreciates the complexity of intercellular communication. Though miRNAs may be critically involved in angiogenesis, their role in platelet secretion and platelet-mediated angiogenesis has not been fully elucidated. The net influence of miRNA and PMPderived miRNA on angiogenesis warrants further study.

\section{Net balance of platelet proangiogenic/antiangiogenic activity}

As previously described, platelets are the source of both stimulators and inhibitors of angiogenesis. Both proangiogenic and antiangiogenic factors are stored in distinct $\alpha$-granules [173, 174], and their release is induced by a selective stimulation of PAR-1 and PAR-4 receptors [173]. Namely, PAR-1 activation leads to VEGF release, whereas stimulation of PAR-4 results in the secretion of antiangiogenic endostatin [173]. Of interest, tumor cell-derived ADP through activation of $\mathrm{P}_{2} \mathrm{Y}_{12}$ receptor induces release of VEGF, but does not affect the secretion of endostatin $[175,176]$. In contrast, thromboxane A2 was documented to facilitate endostatin release, but not VEGF secretion [175]. As platelet activation leads to simultaneous stimulation of antagonistic pathways, it is unclear whether such a subtle mechanism of regulation to selectively release proangiogenic and antiangiogenic factors occurs in vivo. Recently, experiments performed with immunofluorescence microscopy and micro ELISA assays revealed contradictory results [177, 178]. Nevertheless, it should be emphasized that the absence of platelets inhibits the early stages of angiogenesis and results in fewer new vessels in vivo [43, 129]. Platelet releasate stimulates EC migration, and the addition of platelets into the Matrigel model before injection induces angiogenesis [139]. Gastric ulcer healing, that is dependent on angiogenesis, is also inhibited in the presence of thrombocytopenia [114]. Recently, the important role of PMPs and miRNA in the promotion of angiogenesis was documented $[33,133,138,139]$. Platelets also play an important role in the stabilization of newly formed vessels [43]. All of the above data indicate support in the overall stimulatory effect of platelets on tumor angiogenesis. It raises the possibility that interfering with platelet function may be an effective antineoplastic treatment strategy $[179,180]$. Many preclinical and clinical studies dedicated to this idea are ongoing.

Acknowledgments The authors would like to thank Dr. Joanna Kruszewska and Dr. Marta Mysliwiec for their technical substantial contribution in preparing the manuscript.

\section{Compliance with ethical standards}

Conflict of interest The authors declare that they have no conflict of interest. 
Open Access This article is distributed under the terms of the Creative Commons Attribution 4.0 International License (http:// creativecommons.org/licenses/by/4.0/), which permits unrestricted use, distribution, and reproduction in any medium, provided you give appropriate credit to the original author(s) and the source, provide a link to the Creative Commons license, and indicate if changes were made.

\section{References}

1. Bizzozero, J. (1882). Über einen neunen formbestandteil des blutes und dessen rolle bei der thrombose und blutgerinnung. Virchows Archiv für Pathologische Anatomie und Physiologie und für Klinische Medizin, 90, 262-332.

2. Geatano, G. (2001). Historical overview of the role of platelets in hemostasis and thrombosis. Heamatologica, 86, 349-356.

3. Billroth, T. (1878). Lectures on surgical pathology and therapeutics: a new handbook for students and practitioners (p. 355). London: The New Sydenham Society.

4. Mac Kay, W. (1930). The blood platelet: its clinical significance. Quartely Journal of Medicine, 24, 285-293.

5. Zacharski, L. R., Wojtukiewicz, M. Z., Costantini, V., Ornstein, D. L., \& Memoli, V. A. (1992). Pathways of coagulation/fibrinolysis activation in malignancy. Seminars in Thrombosis and Hemostasis, 18, 104-116.

6. Miller, S. P., Sanchez-Avalos, J., Stefanski, T., \& Zuckerman, L. (1967). Coagulation disorders in cancer I. Clinical and laboratory studies. Cancer, 20, 1452-1465.

7. Edwards, R. L., Rickles, F. R., Moritz, T. E., Henderson, W. G., Zacharski, L. R., Forman, W. B., et al. (1987). Abnormalities of blood coagulation tests in patients with cancer. American Journal of Clinical Pathology, 88, 596-602.

8. Rickles, F. R., Levine, M., \& Edwards, R. L. (1992). Hemostatic alterations in cancer patients. Cancer Metastasis Review, 11, 237-248.

9. Francis, J. L., Biggerstaff, J., \& Amirkhosravi, A. (1998). Hemostasis and malignancy. Seminars in Thrombosis and Hemostasis, 24, 93-109.

10. Wojtukiewicz, M. Z., Sierko, E., \& Kisiel, W. (2007). The role of hemostatic system inhibitors in malignancy. Seminars in Thrombosis and Hemostasis, 33, 621-641.

11. Costantini, V., Zacharski, L. R., Moritz, T. E., \& Edwards, R. L. (1990). The platelet count in carcinoma of the lung and colon. Thrombosis and Haemostasis, 64, 501-505.

12. Moller-Pedresen, L., \& Milman, N. (1996). Prognostic significance of thrombocytosis in patients with primary lung cancer. European Respiratory Journal, 9, 1826-1830.

13. Ikeda, M., Furukawa, H., Imamura, H., Shimizu, J., Ishida, H., Masutani, S., et al. (2002). Poor prognosis associated with thrombocytosis in patients with gastric cancer. Annals of Surgical Oncology, 9, 287-291.

14. Symbas, N. P., Townsend, M. F., El, G. R., Keane, T. E., Graham, S. D., \& Petros, J. A. (2000). Poor prognosis associated with thrombocytosis in patients with renal cell carcinoma. BJU International, 86, 203-207.

15. Ribeiro, M., Ruff, P., \& Falkson, G. (1997). Low serum testosterone and a younger age predict for a poor outcome in metastatic prostate cancer. American Journal of Clinical Oncology, 20, 605608

16. Lopez, A., Daras, V., Cross, P. A., Robertson, G., Beynon, G., \& Monaghan, J. M. (1994). Thrombocytosis as a prognostic factor in women with cervical cancer. Cancer, 74, 90-92.
17. Gücer, F., Moser, F., Tamussino, K., Reich, O., Haas, J., Arikan, G., et al. (1998). Thrombocytosis as a prognostic factor in endometrial carcinoma. Gynecologic Oncology, 70, 210-214.

18. Zeimet, A. G., Marth, C., Muller Holzner, E., Daxenbichler, G., \& Dapunt, O. (1994). Significance of thrombocytosis in patients with epithelial ovarian cancer. American Journal Obstetrics \& Gynecology, 170, 549-554.

19. Nakano, T., Fujii, J., Tamura, S., Hada, T., \& Higashino, K. (1986). Thrombocytosis in patients with malignant mesothelioma. Cancer, 58, 1699-1701.

20. Gao, L., Zhang, H., Zhang, B., Zhang, L., \& Wang, C. (2017). Prognostic value of combination of preoperative platelet count and mean platelet volume in patients with resectable non-small cell lung cancer. Oncotarget. doi:10.18632/oncotarget.14921.

21. Wang, Y. H., Deng, S. J., Yang, Y. D., Yao, N., Zhao, J. M., Min, G. T., et al. (2017). The pretreatment thrombocytosis may predict prognosis of patients with colorectal cancer: a systematic review and meta-analysis. Biomarkers in Medicine, 11(2), 195-210.

22. Schwartz, R. E. (1999). Platelet counts and prognosis of pancreatic cancer. Lancet, 353, 2158-2159.

23. Slichter, S. J., \& Harker, L. A. (1974). Hemostasis in malignancy. Annals of the New York Academy of Sciences, 230, 252-262.

24. Tang, D. G., \& Honn, K. V. (1994-1995). Adhesion molecules and tumor metastasis: an update. Invasion \& Metastasis, 14, 109-122.

25. Honn, K. V., Tang, G. T., \& Chen, Y. Q. (1992). Platelets and cancer metastasis: more than an epiphenomenon. Seminars in Thrombosis and Hemostasis, 18, 392-415.

26. Gasic, G. J., Gasic, T. B., \& Steward, C. C. (1968). Antimetastatic effects associated with platelet reduction. Proceedings of the National Academy of Sciences USA, 61, 46-52.

27. Nierodzik, M. L., Klepfish, A., \& Karpatkin, S. (1995). Role of platelets, thrombin, integrin IIb-IIIa, fibronectin and von Willebrand factor on tumor adhesion in vitro and metastasis in vivo. Thrombosis and Haemostasis, 74, 282-290.

28. Dvorak, H. F. (1986). Tumors: wounds that do not heal. New England Journal of Medicine, 315, 1650-1659.

29. Folkman, J. (1971). Tumor angiogenesis: therapeutic implications. New England Journal Medicine, 285, 1182-1186.

30. Folkman, J. (1995). Angiogenesis in cancer, vascular, rheumatoid and other diseases. Nature Medicine, 1, 27-31.

31. Wojtukiewicz, M. Z., Sierko, E., Klement, P., \& Rak, J. (2001). The hemostatic system and angiogenesis in malignancy. Neoplasia, 3, 371-384.

32. Zacharski, L. R., Constantini, V., Wojtukiewicz, M. Z., Memoli, V. A., \& Kudryk, B. J. (1990). Anticoagulants as cancer therapy. Seminars in Oncology, 17, 217-227.

33. Sierko, E., \& Wojtukiewicz, M. Z. (2004). Platelets and angiogenesis in malignancy. Seminars in Thrombosis and Hemostasis, 30, 95-108.

34. Wojtukiewicz, M. Z., Sierko, E., \& Rak, J. (2004). Contribution of hemostatic system to angiogenesis in cancer. Seminars in Thrombosis and Hemostasis, 30, 5-20.

35. Sierko, E., Wojtukiewicz, M. Z., Zimnoch, L., Brekken, R., Thorpe, P., \& Kisiel, W. (2011). Co-localization of prothrombin fragment F1+2 and VEGFR-2 bound VEGF in human colon cancer. Anticancer Research, 31, 843-847.

36. D'Asti, E., Huang, A., Kool, M., Meehan, B., Chan, J. A., Jabado, N., et al. (2016). Tissue factor regulation by $\mathrm{miR}-520 \mathrm{~g}$ in primitive neuronal brain tumor cells: a possible link between oncomirs and the vascular tumor microenvironment. American Journal of Pathology, 186(2), 446-459.

37. D'Asti, E., Kool, M., Pfister, S. M., \& Rak, J. (2014). Coagulation and angiogenic gene expression profiles are defined by molecular subgroups of medulloblastoma: evidence for growth factorthrombin cross-talk. Journal of Thrombosis and Haemostasis., 2(11), 1838-1849. 
38. Verheul, H. M. W., Hoekman, K., Luykx-de Bakkerr, E., Eekm, C. A., Folman, C. C., Broxterman, H. J., \& Pinedo, H. M. (1997). Platelet transporter of vascular endothelial growth factor. Clinical Cancer Research, 3, 2187-2190.

39. Wartiovaara, U., Salven, P., \& Mikkola Heta, I. (1998). Peripheral blood platelets express VEGF-C and VEGF which are released during platelet activation. Thrombosis Haemostasis, 80, 171-175.

40. Verheul, H. M. W., Hoekman, K., Lupu, F., Broxterman, H. J., van der Valk, P., Kakkar, A. K., \& Pinedo, H. M. (2000). Platelet and coagulation activation with vascular endothelial growth factor generation in soft tissue sarcomas. Clinical Cancer Research, 6, 166171.

41. Möhle, R., Green, D., Moore, R. L., Nachman, R. L., \& Raffi, S. (1997). Constitutive production of thrombin-induced release of vascular endothelial growth factor by human megakaryocytes and platelets. Proceedings of the National Academy of Sciences USA, 94, 663-669.

42. Pipli-Synestos, E., Papadimitriou, E., \& Maragoudakis, M. E. (1998). Evidence that platelets promote tube formation by endothelial cells on Matrigel. British Journal of Pharmacology, 125, 12521257.

43. Kisucka, J., Butterfield, C.E., Duda, D.G., Eichenberger, S.C., Saffaripour, S., \& Ware, J. (2006). Platelets and platelet adhesion support angiogenesis while preventing excessive hemorrhage. Proceedings of the National Academy of Sciences USA, 103, 855-860.

44. Andrews, R. K., Shen, Y., Gardiner, E. E., \& Berndt, M. C. (2001). Platelet adhesion receptors and (patho)physiological thrombus formation. Histology and Histopathology, 16, 969-980.

45. Chen, H., Locke, D., Liu, Y., \& Kahn, M. L. (2002). The platelet receptor GPVI mediates both adhesion and signaling responses to collagen in a receptor density-dependent fashion. The Journal of Biological Chemistry, 277, 3011-3019.

46. Kamata, T., \& Takada, Y. (2001). Platelet integrin alphaIIbbeta3ligand interactions: what we learn from the structure? International Journal of Hematology, 74, 382-389.

47. Coughlin, S. R. (1999). Protease-activated receptors and platelet function. Thrombosis and Haemostasis, 82, 353-356.

48. Di Virgilio, F., Chiozzi, P., Ferrari, D., Falzoni, S., Sanz, J. M., Morelli, A., et al. (2001). Nucleotide receptors: an emerging family of regulatory molecules in blood cells. Blood, 97, 587-600.

49. Ruggeri, Z. M., \& Mendolicchio, G. L. (2007). Adhesion mechanisms in platelet function. Circulation Research, 100(12), 1673-1685.

50. Farndale, R. W. (2006). Collagen-induced platelet activation. Blood Cells, Molecules and Diseases, 36, 162-165.

51. Fredrickson, B. J., Dong, J. F., McIntire, L. V., \& Lopez, J. A. (1998). Shear-dependent rolling on von Willebrand factor of mammalian cells expressing the platelet glycoprotein Ib-IX-V complex. Blood, 92, 449-461.

52. Heemskerk, J. W. M., Bevers, E. M., \& Lindhout, T. (2002). Platelet activation and blood coagulation. Thrombosis and Heamostasis, 88, 186-193.

53. Hartwig, J. M., \& DeSisto, M. (1991). The cytoskeleton of the resting human blood platelets: structure of the membrane skeleton and its attachment to actin filaments. The Journal of Cell Biology, $112,407-425$.

54. Serrano, K., \& Devine, D. V. (2002). Intracellular factor XIII crosslinks platelet cytoskeletal elements upon platelet activation. Thrombosis and Haemostasis, 88, 315-320.

55. Thon, J. N., \& Italiano, J. E. (2012). Platelets: production, morphology and ultrastructure. Handbook of Experimental Pharmacology, 210, 3-22.

56. Rendu, F., \& Brohard-Bohn, B. (2001). The platelet release reaction: granules' constituents, secretion and functions. Platelets, 12, 261-273.
57. Menter, D. G., Tucker, S. C., Kopetz, S., Sood, A. K., Crissman, J. D., \& Honn, K. V. (2014). Platelets and cancer: a casual or causal relationship: revisited. Cancer Metastasis Review, 33(1), 231269.

58. Kato, N., Yasukawa, K., Onozuka, T., \& Kimura, K. (1999). Paraneoplastic syndromes of leukocytosis, thrombocytosis, and hypercalcemia associated with squamous cell carcinoma. Journal of Dermatology, 26, 352-358.

59. Estrov, A., Talpaz, M., Mavlight, G., Pazdur, R., Harris, D., Greenberg, S. M., et al. (1995). Elevated plasma thrombopoietic activity in patients with metastatic cancer-related thrombocytosis. American Journal of Medicine, 98, 551-558.

60. Gastl, G., Plante, M., Finstad, C. L., Wong, G. Y., Federici, M. G., Bander, N. H., et al. (1993). High IL-6 levels in ascitic fluid correlate with reactive thrombocytosis in patients with epithelial ovarian cancer. British Journal of Haematology, 83, 433-441.

61. Suzuki, A., Takahashi, T., Nakamura, K., Tsuyuoka, R., Okuno, Y., Enomoto, T., et al. (1992). Thrombocytosis in patients with tumors producing colony-stimulating factor. Blood, 80, 20522059

62. Rafi, S., Shapiro, F., Pettengeli, R., Ferris, B., Nachman, R. L., Moore, M. A., et al. (1995). Human bone marrow microvascular endothelial cells support long-term proliferation and differentiation of myeloid and megakaryocytic progenitors. Blood, 86, 3353-3363.

63. Higashihara, M., Sunaga, S., Tange, T., Oohashi, H., \& Kurokawa, K. (1992). Increased secretion of interleukin-6 in malignant mesothelioma cells from a patient with marked thrombosis. Cancer, 70, 2105-2108.

64. Uppenkamp, M., Makarove, E., Petrasch, S., \& Brittinger, G. (1998). Thrombopoietin serum concentration in patients with reactive and myeloproliferative thrombocytosis. Annals of Hematology, 77, 217-223.

65. Stone, R. L., Nick, A. M., McNeish, I. A., Balkwill, F., Dong, H. H., Bottsford-Miller, J., et al. (2013). Paraneoplastic thrombocytosis in ovarian cancer. The New England Journal of Medicine, 366, 610 618.

66. Sasaki, Y., Takahashi, T., Miyazaki, H., Matsumoto, A., Kato, T., Nakamura, K., et al. (1999). Production of thrombopoietin by human carcinomas and its novel isoforms. Blood, 94, 1952-1960.

67. Baj-Krzyworzecka, M., Majka, M., Pratico, D., Ratajczak, J., Vilaire, G., Kijowski, J., et al. (2002). Platelet-derived microparticles stimulate proliferation, survival, adhesion, and chemotaxis of hematopoietic cells. Experimental Hematology, 30, 450-459.

68. Rafi, S., Mohle, R., Shapiro, F., Frey, B. M., \& Moore, M. A. (1997). Regulation of hematopoiesis by microvascular endothelium. Leukemia \& Lymphoma, 27, 375-386.

69. Wickenhauser, C., Lorenzen, J., Thiele, J., Hillienhof, A., Jungheim, K., Schmitz, B., et al. (1995). Secretion of cytokines (interleukines-1 alpha, -3, and granulocyte-macrophage colony stimulating factor) by normal human bone marrow megakaryocytes. Blood, 85, 685-691.

70. Jones, C. L., Witte, D. P., Feller, M. J., Fugman, D. A., Dorn, G. W., Liebermann, M., \& A. (1992). Response of human megakaryocytic cell line to thrombin: Increase in intracellular free calcium and mitogen release. Biochimica et Biophysica Acta, 1136, 272 282.

71. Avraham, H., Banu, N., Scadden, D. T., Abraham, J., \& Groopman, J. E. (1994). Modulation of megakaryocytopoiesis by human basic fibroblast growth factor. Blood, 83, 2126-2132.

72. Broxmeyer, H. E., Cooper, S., Li, Z. H., Lu, L., Song, H. Y., Kwon, B. S., et al. (1995). Myeloid progenitor cell regulatory effects of vascular endothelial cell growth factor. International Journal of Hematology, 62, 203-215.

73. Tavasolli, M., \& Aoki, M. (1989). Localization of megakaryocytes in the bone marrow. Blood Cells, 15, 3-14. 
74. Feng, W., Madajka, M., Kerr, B. A., Mahabeleshwar, G. H., Whiteheart, S. W., \& Byzova, T. V. (2011). A novel role for platelet secretion in angiogenesis: mediating bone marrow-derived cell mobilization and homing. Blood, 117(14), 3893-3902.

75. Salgado, R., Vermeulen, P. B., Benoy, I., Weytjens, R., Huget, P., Van Marck, E., \& Dirix, L. Y. (1999). Platelet number and interleukin-6 correlate with VEGF but not with bFGF serum levels of advanced cancer patients. British Journal of Cancer, 80, 892-897.

76. Yang, M., Li, K., Ng, M. H., Yuen, P. M., Fok, T. F., Li, C. K., et al. (2003). Thrombospondin-1 inhibits in vitro megakaryocytopoiesis via CD36. Thrombosis Research, 109, 47-54.

77. Bikfalvi, A., \& Han, Z. C. (1994). Angiogenic factors are hematopoietic growth factors and vice versa. Leukemia, 8, 523-529.

78. Falanga, A., \& Rickles, F. R. (1999). Pathophysiology of the thrombophilic state in the cancer patient. Seminars in Thrombosis and Hemostasis, 25, 173-182.

79. Kitagawa, H., Yamamoto, N., Yamamoto, K., Tanoue, K., Kosaki, G., \& Yamazaki, H. (1989). Involvement of platelet membrane glycoprotein $\mathrm{Ib}$ and glycoprotein IIb/IIIa complex in thrombindependent and -independent platelet aggregations induced by tumor cells. Cancer Research, 49, 537-541.

80. Wehmeier, A., Tschope, D., Esser, J., Menzel, C., Nieuwenhuis, H. K., \& Schneider, W. (1991). Circulating activated platelets in myeloproliferative disorders. Thrombosis Research, 61(3), 271278.

81. Blann, A. D., Gurney, M., Wadley, D., Bareford, D., Stonelake, P., \& Lip, G. Y. (2001). Increased soluble P-selectin in patients with haematological and breast cancer: a comparison with fibrinogen, plasminogen activator inhibitor and von Willebrand factor. Blood Coagulation and Fibrinolysis, 12(1), 43-50.

82. Caine, G. J., Lip, G. Y., \& Blann, A. D. (2004). Platelet-derived VEGF, Flt-1, angiopoietin-1 and P-selectin in breast and prostate cancer: further evidence for a role of platelets in tumour angiogenesis. Annals of Medicine, 36(4), 273-277.

83. Wu, L. Q., Zhang, W. J., Niu, J. X., Ye, L. X., Yang, Z. H., Grau, G. E., \& Lou, J. N. (2008). Phenotypic and functional differences between human liver cancer endothelial cells and liver sinusoidal endothelial cells. Journal of Vascular Research, 45, 78-86.

84. Han, X., Guo, B., Li, Y., \& Zhu, B. (2014 Aug 1). Tissue factor in tumor microenvironment: a systematic review. Journal of Hematololgy and Oncology., 7, 54. doi:10.1186/s13045-0140054-8.

85. Jurasz, P., Alonso-Escolano, D., \& Radomski, M. W. (2004). Platelet-cancer interactions: mechanisms and pharmacology of tumor-cell-induced platelet aggregation. British Journal of Pharmacology, 143, 819-826.

86. Bastida, E., Ordinas, A., Giardina, S., \& Jamieson, G. A. (1982). Differentiation of platelet-aggregating effects of human tumor cell lines based on inhibition studies with apyrase, hirudin, and phospholipase. Cancer Research, 42(11), 4348-4352.

87. Raica, M., Cimpean, A. M., \& Ribatti, D. (2008). The role of podoplanin in tumor progression and metastasis. Anticancer Research, 28, 2997-3006.

88. Dang, Q., Liu, J., Li, J., \& Sun, Y. (2014). Podoplanin: a novel regulator of tumor invasion and metastasis. Medical Oncology, 31(9), 24-29.

89. Lowe, K. L., Navarro-Nunez, L., \& Watson, S. P. (2012). Platelet CLEC-2 and podoplanin in cancer metastasis. Thrombosis Research, 129 (suppl 1), S30-S37.

90. Takagi, S., Sato, S., Oh-hara, T., Takami, M., Koike, S., Mishima, Y., et al. (2013). Platelets promote tumor growth and metastasis via direct interaction of between Aggrus/podoplanin and CLEC-2. PloS One, 8, e73609. doi:10.1371/journal.pone.0073609.

91. Demers, M., Krause, D. S., Schatzberg, D., Martinod, K., Voorhees, J. R., Fuchs, T. A., et al. (2012). Cancer predispose neutrophils to release extracellular DNA traps that contribute to cancer-associated thrombosis. Proceedings of the National Academy of Sciences USA, 109, 13076-13081.

92. Karpatkin, S., Nierodzik, M. L., \& Klepfish, A. (1996). A role of platelets, thrombin in cancer. Vessels, 2, 17-23.

93. Pinedo, H. M., Verhaul, H. M. W., D’Amato, R. J., \& Folkman, J. (1998). Involvement of platelets in tumor angiogenesis? Lancet, 352(9142), 1775-1777.

94. Verheul, H. M. W., Jorna, A. S., Hoekman, K., Broxterman, H. J., Gebbink, M. F., \& Pinedo, H. M. (2000). Vascular endothelial growth factor-stimulated endothelial cells promote adhesion and activation of platelets. Blood, 96(13), 4216-4221.

95. Slupsky, J. R., Kalbas, M., Willuwelt, A., Henn, V., Kroczek, R. A., \& Müller-Berghaus, G. (1998). Activated platelets induce tissue factor expression on human umbilical vein endothelial cells by ligation of CD40. Thrombosis and Haemostasis, 80(6), 10081014.

96. Karmann, K., Min, W., Fanslow, W.C., \& Pober, J. S. (1996), Activation and homologous desensitization of human endothelial cells by CD40 ligand, tumor necrosis factor, and interleukin 1 . Journal of Experimental Medicine,184(1), 173-182.

97. Rafii, D. C., Psaila, B., Butler, J., Jin, D. K., \& Lyden, D. (2008). Regulation of vasculogenesis by platelet-mediated recruitment of bone marrow-derived cells. Arteriosclerosis, Thrombosis, and Vascular Biology, 28, 217-222.

98. Klement, G. L., Yip, T. T., Cassiola, F., Kikuchi, L., Cervi, D., Podust, V., et al. (2009). Platelets actively sequester angiogenesis regulators. Blood, 113, 2835-2842.

99. Kuznetsov, H. S., Marsh, T., Markens, B. A., Castaño, Z., GreeneColozzi, A., Hay, S. A., et al. (2012). Identification of luminal breast cancers that establish a tumor-supportive microenvironment defined by proangiogenic platelets and bone marrow-derived cells. Cancer Discovery, 2, 1150-1165.

100. Best, M. G., Sol, N., Kooi, I., Tannous, B. A., Wesseling, P., \& Wurdinger, T. (2015). RNA-Seq of tumor-educated platelets enables blood-based pan-cancer, multiclass, and molecular pathway cancer diagnostics. Cancer Cell, 28, 666-676.

101. Banks, R. E., Forbes, M. A., Kinsey, S. E., Stanley, A., Ingham, E., Walters, C., et al. (1998). Release of the angiogenic cytokine vascular endothelial growth factor (VEGF) from platelets: significance for VEGF measurements and cancer biology. British Journal of Cancer, 77, 956-964.

102. Caine, G. J., Lip, G. Y., Stonelake, P. S., Ryan, P., \& Blann, A. D. (2004). Platelet activation, coagulation and angiogenesis in breast and prostate carcinoma. Thrombosis and Haemostasis, 92, 185-190.

103. McDowell, G., Temple, I., Li, C., Kirwan, C. C., Bundred, N. J., McCollum, C. N., et al. (2005). Alteration in platelet function in patients with early breast cancer. Anticancer Research, 25, 39633966.

104. Werther, K., Christensen, I. J., \& Nielsen, H. J. (2002). Determination of vascular endothelial growth factor (VEGF) in circulating blood: significance of various leukocytes and platelets. Scandinavian Journal of Clinical and Laboratory Investigation, 62, 343-350.

105. Jelkman, W. (2001). Pitfalls in the measurement of circulating vascular endothelial growth factor. Clinical Chemistry, 47, 617-623.

106. Kim, S. J., Choi, I. K., Park, K. H., Yoon, S. Y., Oh, S. C., Seo, J. H., et al. (2004). Serum vascular endothelial growth factor per platelet count in hepatocellular carcinoma: correlations with clinical parameters and survival. Journal of Clinical Oncology, 34, 184-190.

107. Brekken, R. A., Huang, X., King, S. W., \& Thorpe, P. E. (1998). Vascular endothelial growth factor as a marker of tumor endothelium. Cancer Research, 58, 1952-1959.

108. Chen, F. H., Crist, S. A., Zhang, G. J., Iwamoto, Y., \& See, W. A. (2002). Interleukin-6 production by human bladder tumor cell lines is up-regulated by bacillus Calmatte-Guerin through nuclear 
factor-kappaB and Ap-1 via an early pathway. Journal of Urology, 168, 786-797.

109. Brock, T. A., Dvorak, H. F., \& Senger, D. R. (1991). Tumor secreted vascular permeability factor increases cytosolic $\mathrm{Ca}^{2+}$ and von Willebrand factor release in human cells. American Journal of Pathology, 138, 213-221.

110. Thurston, G., Rudge, J. S., Ioffe, E., Zhou, H., Ross, L., Croll, S. D., et al. (2000). Angiopoietin-1 protects the adult vasculature against plasma leakage. Nature Medicine, 6, 460-463.

111. Wojtukiewicz, M. Z., Hempel, D., Sierko, E., Tucker, S. C., \& Honn, K. V. (2016). Thrombin-unique coagulation system protein with multifaceted impacts on cancer and metastasis. Cancer Metastasis Review, 35(2), 213-233.

112. Wojtukiewicz, M. Z., Hempel, D., Sierko, E., Tucker, S. C., \& Honn, K. V. (2015). Protease-activated receptors (PARs)-biology and role in cancer invasion and metastasis. Cancer Metastasis Review, 34(4), 775-796.

113. Clauss, M., Gerlach, M., Gerlach, H., Brett, J., Wang, F., Familletti, P. C., et al. (1990). Vascular permeability factor: a tumor-derived polypeptide that induces endothelial cell and monocyte procoagulant activity, and promotes monocyte migration. The Journal of Experimental Medicine, 172(6), 1535-1545.

114. Ma, L., Perini, R., McKnight, W., Klein, A., Hollenberg, M.D., \& Wallace, J.L. (2005). Proteinase-activated receptors 1 and 4 counter-regulate endostatin and VEGF release from human platelets. Proceedings of the National Academy of Sciences USA, 102, 216-220.

115. Wijelath, E. S., Murray, J., Rahman, S., Patel, Y., Ishida, A., Strand, K., et al. (2002). Novel vascular endothelial growth factor binding domains of fibronectin enhance vascular endothelial growth factor biological activity. Circulation Research, 91(1), 25-31.

116. Balkwill, F., \& Mantovani, A. (2001). Inflammation and cancer: back to Virchow? Lancet, 357, 539-545.

117. Coussens, L. M., Raymond, W. W., Bergers, G., Laig-Webster, M., Behrendtsen, O., et al. (1999). Inflammatory mast cells upregulate angiogenesis during squamous epithelial carcinogenesis. Genes \& Development, 13(11), 1382-1397.

118. McMahon, G. A., Petitclerc, E., Stefansson, S., Smith, E., Wong, M. K., Westrick, R. J., et al. (2001). Plasminogen activator inhibitor-1 regulates tumor growth and angiogenesis. The Journal of Biological Chemistry, 276(36), 33964-33968.

119. Bajou, K., Noel, A., Gerard, R. D., Masson, V., Brunner, N., HolstHansen, C., et al. (1998). Absence of host plasminogen activator inhibitor 1 prevents cancer invasion and vascularization. Nature Medicine, 4(8), 923-928.

120. Peterson, J. E., Zurakowski, D., Italiano Jr., J. E., Michel, L. V., Connors, S., Oenick, M., D’Amato, R. J., et al. (2012). VEGF, PF4 and PDGF are elevated in platelets of colorectal cancer patients. Angiogenesis, 15(2), 265-273.

121. Browder, T., Folkman, J., \& Pirie-Shepherd, S. (2000). The hemostatic system as a regulator of angiogenesis. The Journal of Biological Chemistry, 275(3), 1521-1524.

122. Jurasz, P., Alonso, D., Castro-Blanco, S., Murad, F., \& Radomski, M. W. (2003). Generation and role of angiostatin in human platelets. Blood, 102(9), 3217-3223.

123. Jurasz, P., Santos-Martinez, M. J., Radomska, A., \& Radomski, M. W. (2006). Generation of platelet angiostatin mediated by urokinase plasminogen activator: effects on angiogenesis. Journal of Thrombosis and Haemostasis, 4(5), 1095-1106.

124. McEver, R. P. (2001). Adhesive interactions of leukocytes, platelets, and the vessel wall during hemostasis and inflammation. Thrombosis and Haemostasis, 86(3), 746-756.

125. Mast, A. E., Stadanlick, J. E., Lockett, M., Dietzen, D. J., Hasty, K. A., \& Hall, C. L. (2000). Tissue factor pathway inhibitor binds to platelet thrombospondin-1. The Journal of Biological Chemistry., 275(41), 31715-31721.

126. Selheim, F., Fukami, M. H., Holmsen, H., \& Vessbotn, F. S. (2000). Platelet-derived-growth-factor-induced signalling in human platelets: phosphoinositide-3-kinase-dependent inhibition of platelet activation. Biochemical Journal, 350, 469-475.

127. Chui, C. M., Li, K., Yang, M., Chuen, C. K., Fok, T. F., Li, C. K., et al. (2003). Platelet-derived growth factor up-regulates the expression of transcription factors NF-E2, GATA-1 and c-Fos in megakaryocytic cell lines. Cytokine, 21(2), 51-64.

128. Teuscher, E., \& Weidlich, V. (1985). Adenosine nucleotides, adenosine and adenine as angiogenesis factors. Biomedica Biochimica Acta, 44, 493-495.

129. English, D., Welch, Z., Kovala, A. T., Harvey, K., Volpert, O. V., Brindley, D. N., et al. (2000). Sphingosine 1-phosphate released from platelets during clotting accounts for the potent endothelial cell chemotactic activity of blood serum and provides a novel link between hemostasis and angiogenesis. FASEB Journal, 14, 2255 2265 .

130. Freyssinet, J. M. (2003). Cellular microparticles: what are they bad or good for? Journal of Thrombosis and Haemostasis, 1, 16551662 .

131. Rhee, J. S., Black, M., Schubert, U., Fischer, S., Morgenstern, E., Hames, H. P., \& Preissner, K. T. (2004). The functional role of blood platelet components in angiogenesis. Thrombosis and Hemostasis, 92, 394-402.

132. Italiano, J. E., Mairuhu, A. T. A., \& Fleumen Haft, R. (2010). Clinical relevance of microparticles from platelets and megakaryocytes. Current Opinion in Hematology, 17, 578-584.

133. Rak, J. (2010). Microparticles in cancer. Seminars in Thrombosis and Hemostasis, 36, 888-906.

134. Flumenhaft, R. (2006). Formation and fate of platelet microparticles. Blood Cells, Molecules and Diseases, 36, 182-187.

135. Kim, H. K., Sonfg, K. S., Park, Y. S., Kang, Y. H., Lee, Y. J., Lee, K. R., et al. (2003). Elevated levels of circulating platelet microparticles, VEGF, IL-6, and RANTES in patients with gastric cancer: possible role of a metastasis predictor. European Journal of Cancer, 39, 184-191.

136. Ratajczak, J., Wysoczyński-Hajek, F., Janowska-Wieczorek, A., \& Ratajczak, M. Z. (2006). Membrane-derived microvesicles: important and underappreciated mediators of cell-to-cell communication. Leukemia, 20, 1487-1495.

137. Tan, K. T., \& Lip, G. Y. (2005). The potential role of platelet microparticles in atherosclerosis. Thrombosis and Haemostasis, 94, 488-492.

138. Kim, H. K., Song, K. S., Chung, J. H., Lee, K. R., \& Lee, S. N. (2004). Platelet microparticles induce angiogenesis in vitro. British Journal of Haematology, 124, 374-384.

139. Brill, A., Dashevsky, O., Rivo, J., Gozal, Y., \& Varon, D. (2005). Platelet-derived microparticles induce angiogenesis and stimulate post-ischaemic revascularization. Cardiovascular Research, 67, $30-38$.

140. Janowska-Wieczorek, A., Wysoczynski, M., Kijowski, J., Marquez-Crtis, L., Machalinski, B., Ratajczak, J., et al. (2005). Microvesicles derived from activated platelets induce metastasis and angiogenesis in lung cancer. International Journal of Cancer, $113,752-760$.

141. Cloutier, N., Pare, A., Farndale, R. W., Schumacher, H. R., Nigrovic, P. A., Lacroix, S., et al. (2012). Platelets can enhance vascular permeability. Blood, 120, 1334-1343.

142. Prokopi, M., Pula, G., Mayr, U., Devue, C., Gallagher, J., Xiao, Q., et al. (2009). Proteome analysis reveals presence of platelet microparticles in endothelial progenitor cell cultures. Blood, 114, 723-732. 
143. Li, X., \& Cong, H. (2009). Platelet-derived microparticles and the potential of glycoprotein IIb/IIIa antagonists in treating acute coronary syndrome. Texas Heart Institute Journal, 36, 134-139.

144. Martinez, M. C., \& Andriantsitohaina, R. (2011). Microparticles in angiogenesis: therapeutic potential. Circulation Research, 109, $110-119$.

145. Dashevsky, O., Varon, D., \& Brill, A. (2009). Platelet-derived microparticles promote invasiveness of prostate cancer cells via upregulation of MMP-2 production. International Journal of Cancer, 124, 1773-1777.

146. Seiki, M. (2003). Membrane-type 1 metalloproteinase: a key enzyme for tumor invasion. Cancer Letters, 194, 1-11.

147. Cocucci, E., Racchetti, G., \& Meldolesi, J. (2009). Shedding microvesicles: artefacts no more. Trends in Cell Biology., 19(2), 43-51.

148. Risitano, A., Beaulieu, L. M., Vitseva, O., \& Freedman, J. E. (2012). Platelets and platelet-like particles mediate intercellular RNA transfer. Blood, 119(26), 6288-6295.

149. Diehl, P., Fricke, A., Sander, L., Stamm, J., Bassler, N., Htun, N., et al. (2012). Microparticles: major transport vehicles for distinct microRNAs in circulation. Cardiovascular Research, 93(4), 633-644.

150. Herranz, H., \& Cohen, S. M. (2010). MicroRNAs and gene regulatory networks: managing the impact of noise in biological system. Genes \& Development, 24, 1339-1344.

151. Czech, B., \& Hannon, G. J. (2011). Small RNA sorting: matchmaking for argonuates. Nature Reviews Genetics, 12, 19-31.

152. Denli, A. M., Tops, B. B., Plasterk, R. H., Ketting, R. F., \& Hannon, G. J. (2004). Processing of primary microRNA by the microprocessor complex. Nature, 432, 231-235.

153. Lund, E., Guttinger, S., Calado, A., Dahlberg, J. E., \& Kutay, U. (2004). Nuclear export of microRNA precursors. Science, 303, 95-98.

154. Diederiche, S., \& Haber, D. A. (2007). Dual role for argonuates in microRNA processing and posttranscriptional regulation of microRNA expression. Cell, 131, 1097-1108.

155. Ghildiyal, M., Xu, J., Seitz, H., Weng, Z., \& Zamore, P. D. (2010). Sorting of Drosophila small silencing RNAs partitions microRNA* strands into the RNA interference pathway. RNA, $16,43-56$.

156. Landry, P., Plante, I., Ouellet, D. L., Perron, M. P., Rousseau, G., \& Provost, P. (2009). Existence of a microRNA pathway in anucleate platelets. Nature Structural \& Molecular Biology, 16(9), 961-966.

157. Ple', H., Landry, P., Benham, A., Coarfa, C., Gunaratne, P. H., \& Provost, P. (2012). The repertoire and features of human platelet microRNAs. PloS One. doi:10.1371/journal.pone.0050746 Accessed 25 December 2012.

158. Kondkar, A. A., Bray, M. S., Leal, S. M., Nagalla, S., Liu, D. J., \& Jin, Y. (2010). VAMP8/endobrevin is overexpressed in hyperreactive human platelets: suggested role for platelet microRNA. Journal of Thrombosis and Haemostasis, 8(2), 369-378.

159. Nagalla, S., Shaw, C., Kong, X., Kondkar, A. A., Edelstein, L. C., Ma, L., et al. (2011). Platelet microRNA-mRNA coexpression profiles correlate with platelet reactivity. Blood, 117(19), 5189-5197.

160. Arroyo, J. D., Chevillet, J. R., Kroh, E. M., Ruf, I. K., Pritchard, C. C., Gibson, D. F., et al. (2011). Argonaute2 complexes carry a population of circulating microRNAs independent of vesicles in human plasma. Proceedings of the National Academy of Sciences USA, 108(12), 5003-5008.

161. Vickers, K. C., Palmisano, B. T., Shoucri, B. M., Shamburek, R. D., \& Remaley, A. T. (2011). MicroRNAs are transported in plasma and delivered to recipient cells by high-density lipoproteins. Nature Cell Biology, 13(4), 423-433.
162. Valadi, H., Ekström, K., Bossios, A., Sjöstrand, M., Lee, J. J., \& Lötvall, J. O. (2007). Exosome-mediated transfer of mRNAs and microRNAs is a novel mechanism of genetic exchange between cells. Nature Cell Biology, 9(6), 654659.

163. Zernecke, A., Bidzhekov, K., Noels, H., Shagdarsuren, E., Gan, L., Denecke, B., et al. (2009). Delivery of microRNA-126 by apoptotic bodies induces CXCL12-dependent vascular protection. Science Signaling, 2(100), ra81. doi:10.1126/scisignal. 2000610. Dec 8 Accessed 8 December 2009.

164. Boilard, E., Nigrovic, P. A., Larabee, K., Watts, G. F., Coblyn, J. S., Weinblatt, M. E., et al. (2010). Platelets amplify inflammation in arthritis via collagen-dependent microparticle production. Science, 327, 580-583.

165. Gidlöf, O., van der Brug, M., Ohman, J., Gilje, P., Olde, P., Wahlestedt, C., \& Erlinge, D. (2013). Platelets activated during myocardial infarction release functional miRNA, which can be taken up by endothelial cells and regulate ICAM1 expression. Blood, 121, 3908-3917.

166. Laffont, B., Corduan, A., Plé, H., Duchez, A. C., Cloutier, N., Boilard, E., \& Provost, P. (2013). Activated platelets can deliver mRNA regulatory Ago2 $\bullet$ microRNA complexes to endothelial cells via microparticles. Blood, 122(2), 253261.

167. Yi, P., Liang, H., Liu, H., Li, D., Chen, X., Li, L., Zhang, C.-Y., \& Zen, K. (2014). Platelet-secreted microRNA-223 promotes endothelial cell apoptosis induced by advanced glycation end products via targeting the insulin-like growth factor1 receptor. Journal of Immunology, 192, 437-446.

168. Nicoli, S., Standley, C., Walker, P., Hurlstone, A., Fogarty, K. E., \& Lawson, N. D. (2010). MicroRNA-mediated integration of haemodynamics and Vegf signaling during angiogenesis. Nature, 464, 1196-1200.

169. Fish, J. E., Santoro, M. M., Morton, S. U., Yu, S., Yeh, R. F., et al. (2008). miR-126 regulates angiogenic signaling and vascular integrity. Developmental Cell, 15, 272-284.

170. Nicolas, F. E., Pais, H., Schwach, F., Lindow, M., Kauppinen, S., Moulton, V., \& Dalmay, T. (2008). Experimental identification of microRNA-140 targets by silencing and overexpressing miR-140. RNA, 14, 2513-2520.

171. Poliseno, L., Tuccoli, A., Mariani, L., Evangelista, M., Citti, L., Woods, K., et al. (2006). MicroRNAs modulate the angiogenic properties of HUVECs. Blood, 108, 3068-3071.

172. le Sage, C., Nagel, R., Egan, D. A., Schrier, M., Mesman, E., Mangiola, A., et al. (2007). Regulation of the p27/(Kip1) tumor suppressor by miR-221 and niR-222 promotes cancer cell proliferation. EMBO Journal, 26, 3699-3708.

173. Italiano Jr., J. E., Richardson, J. L., Patel-Hett, S., Battinelli, E., Zaslavsky, A., Short, S., et al. (2008). Angiogenesis is regulated by a novel mechanism: pro- and antiangiogenic proteins are organized into separate platelet alpha granules and differentially released. Blood, 111(3), 1227-1233.

174. Cattaneo, M. (2010). New P2Y(12) inhibitors. Circulation, 121, 171-179.

175. Batinelli, E. M., Markens, B. A., \& Italiano Jr., J. E. (2011). Release of angiogenesis regulatory proteins from platelet alpha granules: modulation of physiologic and pathologic angiogenesis. Blood, 118, 1359-1369.

176. Bambace, N. M., Levis, J. E., \& Holmes, C. E. (2010). The effect of P2Y-mediated platelet activation on the release of VEGF and endostatin from platelets. Platelets, 21, 85-93.

177. Kamykowski, J., Carlton, P., Sehgal, S., \& Storie, B. (2011). Quantitative immunofluorescecnce mapping reveales little functional coclustering of proteins within platelets alpha-granules. Blood, 118, 1370-1378. 
178. Jonnalagadda, D., Izu, L. T., \& Whiteheart, S. W. (2012). Platelet secretion is kinetically heterogeneous in an agonist-responsive manner. Blood, 120, 5209-5216.

179. Sierko, E., \& Wojtukiewicz, M. Z. (2007). Inhibition of platelet function: does it offer a chance of better cancer progression control. Seminars in Thrombosis and Hemostasis, 33, 712-721.
180. Wojtukiewicz, M. Z., Sierko, E., \& Zacharski, L. R. (2004). Interfering with hemostatic system components: possible new approaches to antiangiogenic therapy. Seminars in Thrombosis and Hemostasis, 30, 145-156. 